\title{
Wet chemical development of CuO/GO nanocomposites: its augmented antimicrobial, antioxidant, and anticancerous activity
}

\author{
Kunal Biswas ${ }^{1} \cdot$ Yugal Kishore Mohanta ${ }^{2} \cdot$ Awdhesh Kumar Mishra $^{3} \cdot$ Abdullah G. Al-Sehemi $^{4}$. \\ Mehboobali Pannipara ${ }^{4} \cdot$ Avik Sett $^{5} \cdot$ Amra Bratovcic $^{6} \cdot$ Debashis De $^{7} \cdot$ Bibhu Prasad Panda $^{8} \cdot$ Satya Kumar Avula $^{9}$. \\ Tapan Kumar Mohanta ${ }^{9} \cdot$ Ahmed Al-Harrasi $^{9}$
}

Received: 4 August 2021 / Accepted: 10 September 2021 / Published online: 11 December 2021

(c) The Author(s) 2021

\begin{abstract}
This study employed a bottom-up technique to synthesize copper oxide $(\mathrm{CuO})$ nanoparticles over hydrophilic graphene oxide (GO) nanosheets. The $\mathrm{CuO} / \mathrm{GO}$ nanocomposite has been prepared using two selected precursors of copper nitrate and citric acid with an intermittent mixing of GO solutions. The synthesized Nanocomposites were characterized using different biophysical techniques like FT-IR, NMR, FE-SEM, and HR-TEM analyses. FT-IR analyses confirm the nanocomposites' successful formation, which is evident from the functional groups of $\mathrm{C}=\mathrm{C}, \mathrm{C}-\mathrm{O}$, and $\mathrm{Cu}-\mathrm{C}$ stretching vibrations. Morphological analyses reveal the depositions of $\mathrm{CuO}$ nanoparticles over the planar rough $\mathrm{GO}$ sheets, which has been elucidated from the FE-SEM and HR-TEM analyses supported by respective EDAX analyses. The antimicrobial activities have been evident from the surface roughness and damages seen from the FE-SEM analyses. The CuO/GO sheets were tested against Gram-positive (e.g., Staphylococcus aureus) and Gram-negative (Escherichia coli, Pseudomonas aeruginosa). It is evident that the intrinsic antibacterial activity of $\mathrm{CuO} / \mathrm{GO}$ sheets, when combined in equal proportions, elicited a robust antibacterial activity when tested over Gram -ve representative bacteria Escherichia coli. The antioxidant behaviour of synthesized CuO/GO nanocomposite was evaluated by scavenging the free radicals of DPPH and ABTS. Moreover, the cytotoxic activity was also studied against epidermoid carcinoma cell line A-431. A brief mathematical formulation has been proposed in this study to uncover the possibilities of using the nanocomposites as potential drug candidates in theranostic applications in disease treatment and diagnosis. This study would help uncover the electronic properties that play in the nano-scaled system at the material-bio interface, which would aid in designing a sensitive nano-electromechanical device bearing both the therapeutic and diagnostic attributes heralding a new horizon in the health care systems.
\end{abstract}

These authors contributed equally: Kunal Biswas, Yugal Kishore Mohanta, Awdhesh Kumar Mishra

Tapan Kumar Mohanta

tapan.mohanta@unizwa.edu.om

$\triangle$ Ahmed Al-Harrasi

aharrasi@unizwa.edu.om

1 Department of Biotechnology, Maulana Abul Kalam Azad University of Technology, Kolkata, West Bengal 741249, India

2 Department of Applied Biology, School of Biological Sciences, University of Science and Technology Meghalaya, Ri-Bhoi 793101, India

3 Department of Biotechnology, Yeungnam University, Gyeongsan, Gyeongsangbuk-do, Republic of Korea

4 Department of Chemistry, King Khalid University, Abha 61413, Saudi Arabia
5 Department of Electronics and Electrical Communication Engineering, IIT Kharagpur, Kharagpur 721302, India

6 Department of Physical Chemistry and Electrochemistry, Faculty of Technology, University of Tuzla, Univerzitetska 8, 75000 Tuzla, Bosnia and Herzegovina

7 Department of Computer Science and Engineering, Maulana Abul Kalam Azad University of Technology, Kolkata, West Bengal 741249, India

8 Centre for Environmental Sciences, Siksha O Anusandhan University, Bhubaneswar, India

9 Natural and Medical Sciences Research Centre, University of Nizwa, Nizwa 616, Oman 


\section{Graphical Abstract}

A bottom-up technique has been employed to synthesize copper oxide $(\mathrm{CuO})$ nanoparticles over hydrophilic graphene oxide (GO) nanosheets. The synthesized $\mathrm{CuO} / \mathrm{GO}$ nanocomposites exhibited potential antibacterial (human pathogens), antioxidant (DPPH \& ABTS) and anticancer (epidermoid carcinoma A-431) activity. This study would help uncover the electronic properties that play in the nano-scaled system at the material-bio interface, which would aid in designing a sensitive nano-electromechanical device bearing both the therapeutic and diagnostic attributes heralding a new horizon in the health care systems.

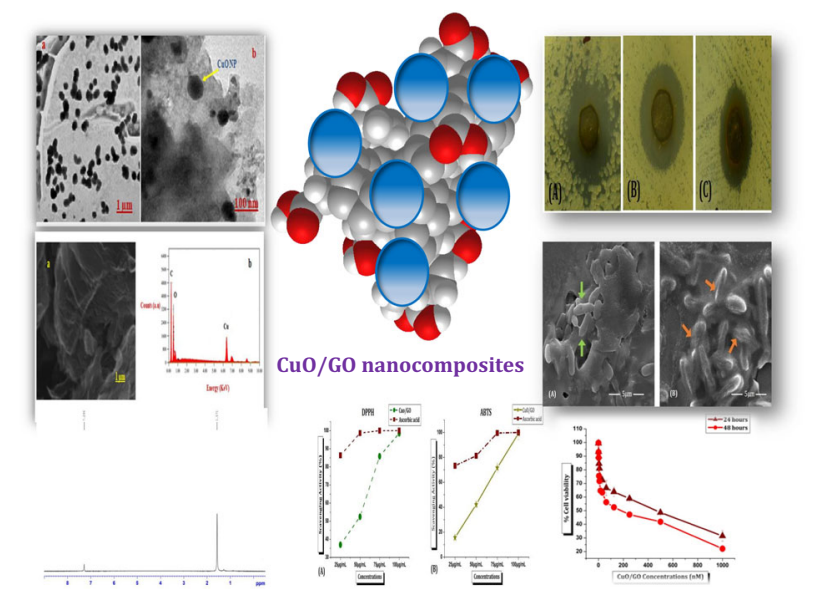

Keywords $\mathrm{CuO} / \mathrm{GO}$ nanocomposite $\cdot$ Biomedical activities $\cdot$ Electro-mechanical device $\cdot$ Nanomedicine

\section{Highlights}

- The CuO/GO nanocomposite has been prepared using two selected precursors of copper nitrate and citric acid with an intermittent mixing of GO solutions.

- $\mathrm{CuO}$ nanoparticles decoration on GO sheets to coincide the enrichment of activity and stability from their cooperation.

- $\mathrm{CuO} / \mathrm{GO}$ nanocomposite has appreciable activity towards pathogenic bacteria, free radicals, and cancer cell lines.

- The as-prepared nanocomposite is proposed as a novel nanomaterial for theranostic activities bearing both therapeutic attributes along with diagnostic nature in the biological domain and healthcare.

\section{Introduction}

Owing to the intrinsic direct band gap nature, p-type attributes, robust electrochemical behaviour, and the lower cost of fabrication, the studies over Copper Oxide $(\mathrm{CuO})$ nanomaterials have seen an exponential rise in different fields applications [1, 2]. Cuprous Oxide $\left(\mathrm{Cu}_{2} \mathrm{O}\right)$ and Cupric Oxides $(\mathrm{CuO})$ are the two prevalent forms of Copper Oxide polymorphism existing in nature, forming the two most important stoichiometric compounds in the entire $\mathrm{CuO}$ systems [3]. The melting point of the intrinsic $\mathrm{CuO}$ is $\sim 1330{ }^{\circ} \mathrm{C}$, which is sparingly soluble in the water. The density of the pure Cupric Oxide is $\sim 6.4 \mathrm{gm}$ per $\mathrm{cm}^{3}$. The direct band gap value of pristine $\mathrm{CuO}$ nanoparticles is basically a p-type semiconductor with a value range of $\sim 1.2-1.85 \mathrm{eV}$, attracting numerous applications from gas sensors for hydrogen, volatile organic compounds, catalysis, and especially in photovoltaic solar cells, electrochemical coatings etc. [4-8]. Owing to such widespread utility in electrochemical and sensing applications, the synthesis of $\mathrm{CuO}$ nanoparticles at laboratory conditions is of paramount importance. In this regard, several techniques are currently employed in the laboratory conditions for the synthesis of $\mathrm{CuO}$ nanoparticles like spray pyrolysis, pulsed laser deposition, plasma-based ion implantations, chemical vapour deposition etc. It has been reported that the selection of the fabrication procedures determines the underlying electrochemical, Physico-chemical, and electro-mechanical properties of the assynthesized $\mathrm{CuO}$ nanoparticles [9-12]. It is well known that Graphene Oxide (GO) nanosheets are hydrophilic in nature owing to their available Oxygen groups linked with the structure, available defect attributes, which make the GO nanosheets perfectly soluble in water for different applications [13]. Several reports have been studied to ascertain the implications of GO sheets in sensor studies 
(Wu et al., 2021), antimicrobial studies, and several biological systems [14].

In this study, the prime focus is to extract the electrochemical, Physico-chemical attributes of the pristine $\mathrm{CuO}$ nanoparticles when combined and decorated in the lattice defects of the GO sheets. The nanocomposites have been studied in the context of designing a robust, novel nano and micro electro-mechanical sensing system owing to its pristine therapeutic and diagnostic properties. The study would highlight the implications of the as-synthesized $\mathrm{CuO} / \mathrm{GO}$ nanocomposites into the treatment of prokaryotic systems of bacteria, which would be further validated into the in-vitro cell lines in laboratory conditions to substantiate the capabilities of the prepared nanocomposites for acting as a potential theranostic material in future.

\section{Material and method}

\subsection{Materials}

The reagents used in the study were of analytical grade and have been purchased from Sigma Aldrich and have been used without further purifications. Reagents include Copper (II) nitrate trihydrate, Sodium Hydroxide $(\mathrm{NaOH})$, Potassium Chloride (KCL), Lead Nitrate and Triton-X 100 respectively. The solvent used in the entire study was double distilled water.

\subsection{Bottom up synthesis of CuO nanoparticles}

In the reaction procedures, $25 \mathrm{ml}$ of $0.2 \mathrm{~mol} \mathrm{~L}^{-1}$ Copper (II) nitrate trihydrate solution was mixed in a solution containing $25 \mathrm{ml}$ of $0.3 \mathrm{~mol} \mathrm{~L}^{-1} \mathrm{NaOH}$ solution, which has been thoroughly mixed into a solution containing $0.003 \mathrm{~mol} \mathrm{~L}^{-1}$ of Triton-X 100 with the regular and constant stirring mechanism. The resulting mixture has been autoclaved at $\sim 200^{\circ} \mathrm{C}$ for $5 \mathrm{~h}$. and post vigorous stirring for $\sim 3 \mathrm{~h}$. The resulting precipitates were then washed thoroughly with the deionized water and absolute ethanol after cooling the stirred samples for $3 \mathrm{~h}$. The step of precipitate washing has been followed with the effective drying in the oven at $\sim 50{ }^{\circ} \mathrm{C}$ for $7-8 \mathrm{~h}$. [15].

\subsection{Preparation of GO sheets}

Graphene Oxide sheets were prepared following the conventional hummers method [16].

\subsection{Preparation of the $\mathrm{CuO} / \mathrm{GO}$ nanocomposites}

$\mathrm{CuO}$ solutions of $5 \mathrm{ml}$ were mixed in a vessel containing GO solutions of $50 \mathrm{ml}$ volume, which is followed by the constant stirring of the mixture solution at $100^{\circ} \mathrm{C}$ for $1 \mathrm{~h}$. Upon continuous stirring of the mixture solution at such temperature, it formed gel-like morphology that looks like a light, fluffy mass of both the components of $\mathrm{CuO}$ and $\mathrm{GO}$ compositions. The step is followed by annealing at $200{ }^{\circ} \mathrm{C}$ for $\sim 2 \mathrm{~h}$. The resulting product has been subjected to grinding for further characterization approaches (Bezza, F. A et al., 2020).

\subsection{Characterizations of the $\mathrm{CuO/GO}$ nanocomposites}

The as-prepared nanocomposites of $\mathrm{CuO} / \mathrm{GO}$ have been subjected to characterizations like Fourier Transform Infra-Red spectroscopy (FT-IR) (Bruker ATR) at $400 \mathrm{~cm}^{-1}$ to $4000 \mathrm{~cm}^{-1}$ scanning range for ascertaining the available functional groups in the composites. Nuclear Magnetic Resonance (NMR) has been further employed to characterize different local magnetic fields around the atomic nuclei of the nanocomposites. The spectroscopic examinations were further extended to examine morphological features of the as-prepared composite using FESEM and HR-TEM analyses, which is further coupled by Energy Dispersive X-Ray Spectroscopy (EDAX) analyses for the confirmation of the composite formation.

\subsection{Antibacterial Activity of the CuO/GO nanocomposites}

\subsubsection{Bacterial strains}

The three species of human pathogenic bacteria, Staphylococcus aureus, Escherichia coli, and Pseudomonas aeruginosa were used in the antibacterial assay.

\subsubsection{Micro broth dilution method and agar well diffusion method of antibacterial assays}

Muller Hinton (MH) broth medium of $5 \mathrm{ml}$ has been inoculated with the small colony of each test bacterial strain from its respective stock solution under appropriate aseptic conditions. The inoculated tubes were incubated overnight at $37^{\circ} \mathrm{C}$ on a rotary shaker at $200 \mathrm{rpm}$. The evaluation of the antibacterial activity of the $\mathrm{CuO} / \mathrm{GO}$ nanocomposites against the selected pathogenic bacteria was regulated using a well diffusion assay with Muller Hinton Agar (MHA) [17]. Briefly, $100 \mu$ of each bacterium was grown over the processed MHA plates. Test wells of $5 \mathrm{~mm}$ diameter and $3 \mathrm{~mm}$ deep were then formed using a sterile cork borer in the inoculated agar medium. Each well was then filled with $50 \mu \mathrm{l}$ of $\mathrm{CuO} / \mathrm{GO}$ nanocomposites. The antibiotic, Gentamicin, were taken as a positive control. The respective plates were incubated at $37^{\circ} \mathrm{C}$ for $24 \mathrm{~h}$. The diameter of inhibition known as Zone of Inhibition (ZOI) was calculated after incubation, and a net 
diameter of $\sim \geq 8 \mathrm{~mm}$ was considered a positive antibacterial activity of the composites.

Antibacterial was also evaluated employing the micro broth dilution method. The minimum inhibitory concentration (MIC) of the $\mathrm{CuO} / \mathrm{GO}$ nanocomposites on bacterial strains was also assessed. Additional MIC calculations were performed besides conventional MIC assays to ascertain the confirmed antibacterial activities of the nanocomposites, where inhibition proportions of $\geq 90 \%$ were taken into considerations that composite is eliciting augmented and remarkable antibacterial activities in the broth conditions. The test inoculum $(190 \mu \mathrm{l}$; $\left.\mathrm{A}_{600}=0.1\right)$ were incubated in $10 \mu \mathrm{l}$ of different concentrations (two-fold dilution) of the $\mathrm{CuO} / \mathrm{GO}$ nanocomposites, until the level of inhibition was found to be $<50 \%$. Microplate Reader (Bio-Rad, USA) has been employed to determine the microbial growth in the conventional 96-well plates at $600 \mathrm{~nm}$ wavelength. Conventional Laboratory excel calculations were performed to ascertain the numerical MIC values using IC50/IC90 calculations and have been expressed as $\mathrm{IC}_{50}$ values. The zone of inhibition (ZOI) has been expressed in mean $\pm \mathrm{SD}$, and the assays were all repeated in triplicate.

\subsubsection{Microscopic study of antibacterial activity}

The antibacterial activity of $\mathrm{CuO} / \mathrm{GO}$ nanocomposites in terms of physical interaction with pathogenic strains was studied using a Field-emission scanning electron microscope (FE-SEM).

\subsection{Antioxidant activity of CuO/GO nanocomposites}

The antioxidant activity of the $\mathrm{CuO} / \mathrm{GO}$ nanocomposites was evaluated by its radicle scavenging potential.

\subsubsection{DPPH Radical-Scavenging Activity}

The radical scavenging activity of $\mathrm{CuO} / \mathrm{GO}$ nanocomposites was determined using the 1, 1-diphenyl-2-picryl-hydrazil (DPPH) assay with slight modification [18, 19]. Different concentrations $(25,50,75$ and $100 \mu \mathrm{g} / \mathrm{ml})$ of $\mathrm{CuO} / \mathrm{GO}$ nanocomposites were used in the assay. In the experimentations, the positive control has been designated to equivalent concentrations of Ascorbic Acid (AA), and (\%) radical scavenging activity has been used to denote the effective result outcomes. The MIC for DPPH radical scavenging activity was also calculated and expressed as an $\mathrm{IC}_{50}$ valuation.

\subsubsection{2,2-Azino-bis (3-ethylbenzothiozoline-6-sulfonic acid) diammonium salt (ABTS) radical scavenging activity}

Using well-accepted ABTS radical scavenging assays of a particular material, the activity of $\mathrm{CuO} / \mathrm{GO}$ radical scavenging potential has also been determined using the previously described ABTS method [20], using different concentrations $(25,50,75$ and $100 \mu \mathrm{g} / \mathrm{ml})$ of $\mathrm{CuO} / \mathrm{GO}$ nanocomposites. Ascorbic acid at equivalent concentrations was used as a positive control. The MIC for ABTS radical scavenging activity was also calculated and expressed as an $\mathrm{IC}_{50}$.

\subsection{Cytotoxicity study of CuO/GO nanocomposite}

\subsubsection{Cell culture}

Dulbecco's Modified Eagle's Medium (DMEM) has been used for the seeding of epidermoid carcinoma cell line A-431 (NCCS, Pune, India) and has been supplemented with $10 \%$ foetal bovine serum (FBS), which has been incubated at $37^{\circ} \mathrm{C}$ $\left(5 \% \mathrm{CO}_{2}\right)$ for $24 \mathrm{~h}$ for the duration of the assays. The cells were trypsinized using $0.25 \%$ Trypsin-EDTA at a $70-80 \%$ assemblage. Cells were enumerated and then implanted in a 96-well Enzyme-linked immunosorbent assay (ELISA) plate at a density of $5 \times 10^{3}$ cells/well to carry out a dimethyl thiazolyl-diphenyltetrazolium bromide (MTT) assay [21].

\subsubsection{MTT Assay}

$\mathrm{CuO} / \mathrm{GO}$ nanocomposites were assessed for its cytotoxicity analyses using the conventional MTT Assay, wherein the cell lines were incubated with the nanocomposite for 24-48 h. incubation period. In the experimentation, $1 \mathrm{mg} /$ $\mathrm{ml}$ of MTT stock in PBS solution was prepared, and the doxorubicin solution was used as a positive standard. Each cultured disk was supplemented with a $500 \mu \mathrm{l}$ MTT solution $(50 \mu \mathrm{g} / \mathrm{ml}$ MTT in culture medium) and has been left uncovered. The reduced formazan was extracted with the $500 \mu \mathrm{l}$ of DMSO. The cells were incubated for $3 \mathrm{~h}$. and absorbance was calculated at $595 \mathrm{~nm}$ wavelength in a microtiter plate reader (Bio-Rad, USA). Compared to untreated and control cells, the net cell viability has been determined using the \% absorption of the treated cells [22].

\subsection{Mathematical modelling of proposed drug composites (CuO/GO) over biological targets and its pharmacodynamics analysis: a horizon for theranostic applications}

\subsubsection{Concentration-effect model-based drug combinations}

The effectiveness of the drug interaction with the biological targets could be illustrated with the law of mass-action at the region of interaction as shown in below equation:

$\mathrm{C}+\mathrm{R}=\underset{\mathrm{K}_{\mathrm{b}}}{\stackrel{\mathrm{K}_{\mathrm{F}}}{\leftrightarrows}} \mathrm{RC}$ 
Fig. 1 FT-IR of $\mathrm{CuO} / \mathrm{GO}$ nanocomposites
Fig. $2{ }^{13} \mathrm{CNMR}$ spectra of $\mathrm{CuO} /$

GO nanocomposites

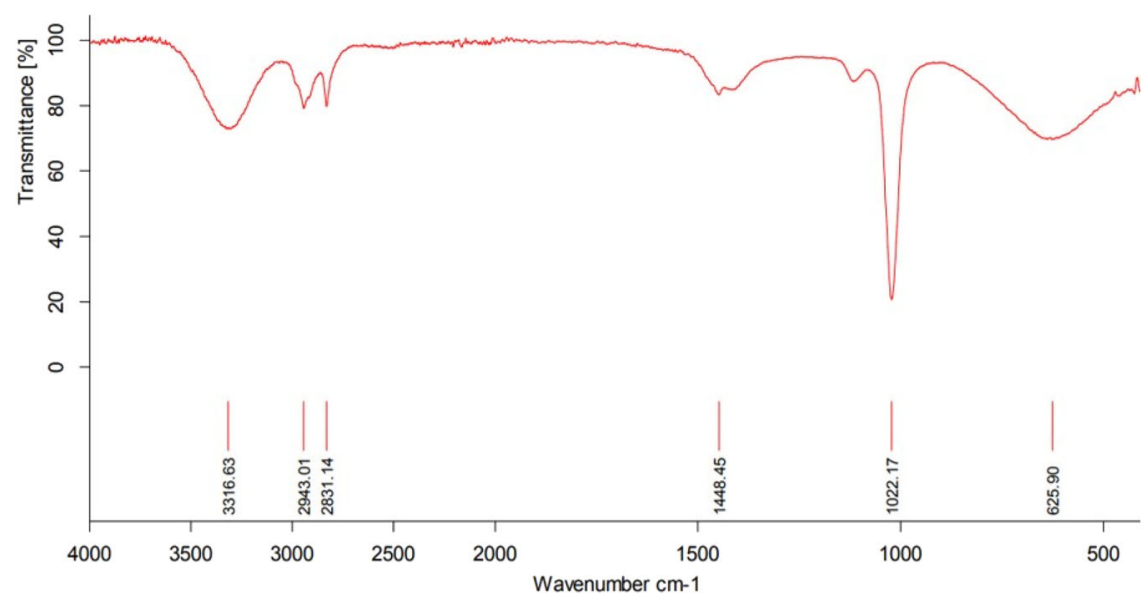

where, ' $C$ ', ' $R$ ' and ' $R C$ ' represent the drug, receptor, and drug-receptor complex, respectively.

Also, at the equilibrium, whenever the forward and backward rates are equal, then the equations stand to which is shown in below equation:

$$
[\mathbf{R C}] /[\mathbf{R}]_{\mathbf{T}}=[\mathbf{C}] / \mathbf{k}_{\mathbf{d}}+[\mathbf{C}]
$$

where $[\mathrm{C}]$ corresponds to concentration and $[\mathrm{R}]_{\mathrm{T}}$ is the receptors total molar concentrations, $\mathrm{k}_{\mathrm{d}}=\mathrm{k}_{\mathrm{b}} / \mathrm{k}_{\mathrm{f}}$ corresponds to the drug dissociation constants and signifies the concentration at which the proposed drug binds to half of the total available receptors [18].

Also, the pharmacodynamics of the drug modelling when the drug interacts with the biological target receptors, which forms the basis of the proposed theranostic device modelling, which can detect and diagnose the available target moieties, could be illustrated by the mathematical modelling as shown in below equation:

$\mathbf{E}(\mathbf{c})=\mathbf{E}_{\max } \mathbf{c}^{\mathbf{n}} / \mathbf{E C}_{\mathbf{5 0}}^{\mathbf{n}}+\mathbf{c}^{\mathbf{n}}$ where the concentration of the drug is denoted by c, whereas the $\mathrm{EC}_{5 \mathrm{O}}$ denotes the concentration at which the drug exhibits half of the drug's maximum response $\left(\mathrm{E}_{\max }\right)$. This parameter is the valuation of the drug's potency, which is proportional to the drug's affinity and its intrinsic efficacy. In the case of Emax, it is regulated by several drug-related aspects and associated parameters like drug efficacy, the quantitative numbers of the target receptors and the nature of relaying of the stimulus, which is required for eliciting sigmoidal drugrelated responses in the desired biological targets.

In this study, the proposed nanocomposites of Copper Oxide $(\mathrm{CuO})$ decorated over Graphene Oxide (GO) sheets are designed to elicit diagnostic and therapeutic activity when treated into several biological targets like cancer cell lines, bacterial targets etc.

\subsection{Statistical analysis}

All the experimentations of antibacterial, cytotoxicity assays were performed in triplicate. The experimentations 
Fig. 3 FE-SEM and EDAX spectra of $\mathrm{CuO} / \mathrm{GO}$ nanocomposites

Fig. 4 HR-TEM of $\mathrm{CuO} / \mathrm{GO}$ nanocomposites indicating the $\mathrm{CuO}$ deposits over $\mathrm{GO}$ sheets (indicated by arrows)

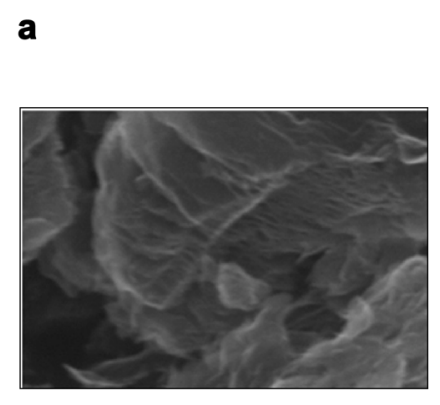

b

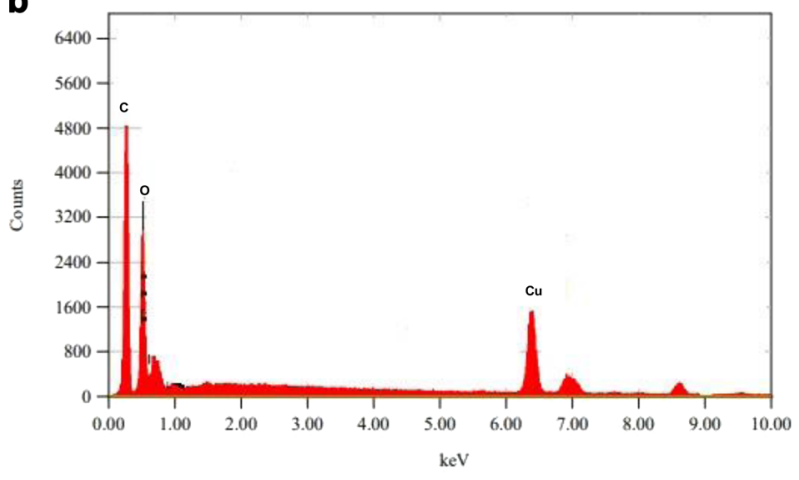

b

a

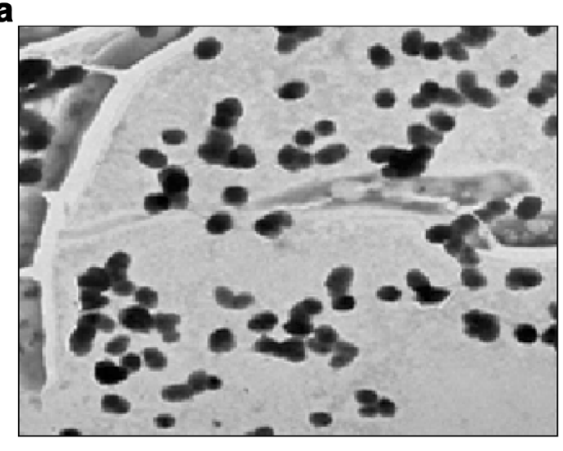

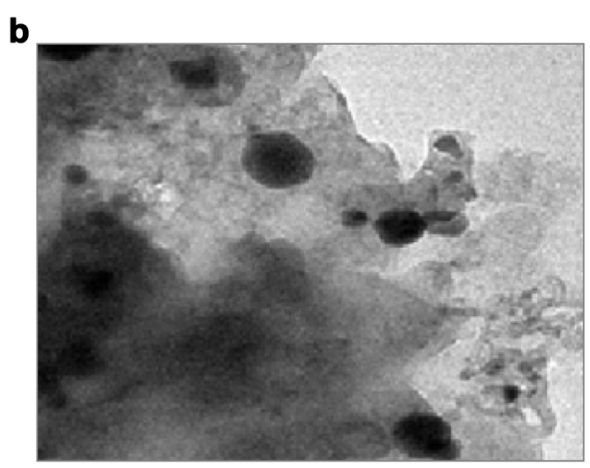

Fig. 5 Antibacterial activity in agar well diffusion method (A) E. coli (B) S. aureus (C) $P$. aeruginosa
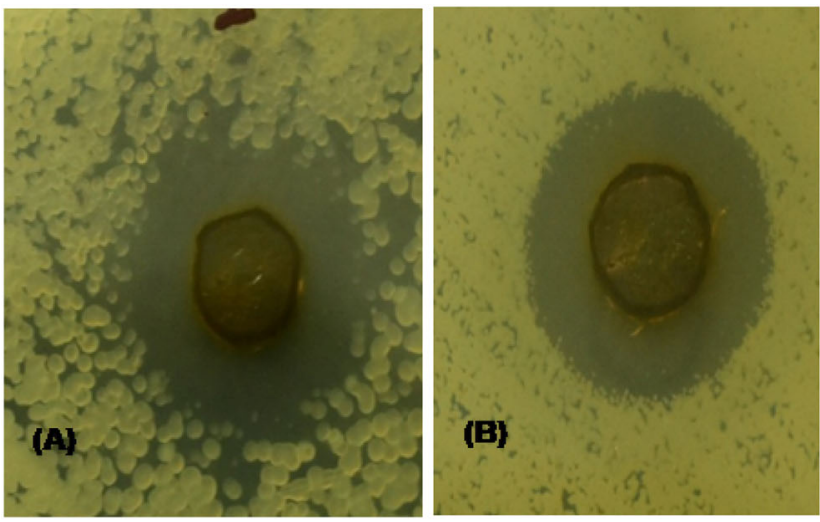

were determined in terms of $\%$ inhibition for antibacterial assays and \% viability assays for cytotoxicity tests compared to the control sets, respectively. The experimentations were statistically determined using the Student's $t$ test of probability $p \leq 0.05$.

\section{Results and Discussion}

\subsection{Fourier transform infra-red spectroscopy (FT-IR)}

It could be seen that the vibrational modes at 606 and 508 $\mathrm{cm}-1$ indicate the $\mathrm{Cu}-\mathrm{O}$ vibrations in the FT-IR plots, as shown in Fig. 1. The peaks in the range of $1300-1420 \mathrm{~cm}^{-1}$ and $2919 \mathrm{~cm}^{-1}$ indicate the stretching vibrations of $\mathrm{C}-\mathrm{H}$ bending. C-O stretching at $1046 \mathrm{~cm}-1$ has also been noticed in the FT-IR plot. It was interesting to note that no $\mathrm{Cu}_{2} \mathrm{O}$ stretching modes were detected in the plot. The broad stretching vibrational modes at 3411 and $1631 \mathrm{~cm}^{-1}$ indicate the O-H vibrations. Such results clearly stated the formation of hydration layers over the $\mathrm{CuO}$ surfaces during the nanocomposite synthesis.

\subsection{Nuclear magnetic resonance (NMR)}

The as-prepared nanocomposites clearly show the formation of differential peak heights in $\mathrm{C}^{13}$ NMR plot as shown in Fig. 2 for different ppm for the formation of local magnetic 
moment around the nuclei of each participating atomic nuclei of the nanocomposites of Copper and Carbon, respectively. Such intermixing magnetic moment states in the ${ }^{13} \mathrm{C}$ NMR plot exhibit the successful formation of the desired nanocomposites. Further exploration of the interacted oxidation states using X-ray Photoelectron Spectroscopy (XPS) of $\mathrm{Cu}$ and Carbon would help uncover the mixture's real oxidation states.

\subsection{FE-SEM analysis}

As shown in Fig. 3, the characteristic FE-SEM analyses could be noticed that successful formation of the $\mathrm{CuO} / \mathrm{GO}$ sheets has been formed. The results are in parity with the previous publications in similar fields. The surface morphological features of the $\mathrm{CuO} / \mathrm{GO}$ sheets have been substantiated using EDAX analyses, which exhibited $\mathrm{Cu}$ peaks and $\mathrm{C}$ peaks in good proportions.

\subsection{HR-TEM analysis}

The internal morphology of the as-prepared nanocomposites has exhibited an enwrapped GO sheets over the $\mathrm{CuO}$ nanoparticles, as seen in Fig. 4. The images could be easily

Table 1 Antibacterial activity of $\mathrm{CuO} / \mathrm{GO}$ nanocomposite

\begin{tabular}{llll}
\hline $\begin{array}{l}\text { Name of the } \\
\text { test strain }\end{array}$ & $\begin{array}{l}\text { Mean zone of } \\
\text { inhibition } \pm \mathrm{SD} \\
\text { (in mm) }\end{array}$ & $\begin{array}{l}\text { Percentage of } \\
\text { inhibition }(\%) \\
\pm \mathrm{SD}\end{array}$ & $\begin{array}{l}\mathrm{MIC} \\
\mathrm{IC}_{50}(\mu \mathrm{g} / \mathrm{ml})\end{array}$ \\
\hline $\begin{array}{l}\text { Staphylococcus } \\
\text { aureus }\end{array}$ & $18.57 \pm 0.05$ & $94.03 \pm 0.54$ & $90.67 \pm 0.32$ \\
$\begin{array}{l}\text { Escherichia coli } \\
\begin{array}{l}\text { Pseudomonas } \\
\text { aeruginosa }\end{array}\end{array}$ & \begin{tabular}{l}
$20.10 \pm 0.16$ \\
\hline
\end{tabular} & $99.37 \pm 0.17$ & $72.98 \pm 0.27$ \\
\hline
\end{tabular}

seen for the formation of the nanocomposites in better proportions. The same features in the HRTEM images indicate that $\mathrm{CuO}$ nanoparticles have been doped and decorated over the GO sheets in an integrating manner.

\subsection{Antibacterial activity}

The antibacterial activity of $\mathrm{CuO} / \mathrm{GO}$ nanocomposite was preliminarily determined by agar well diffusion (AWD) method; against three human pathogenic bacteria $S$. aureus, E. coli and P. aeruginosa as shown in Fig. 5 \& Table 1 . From the zone of inhibition, it was found that $\mathrm{CuO} / \mathrm{GO}$ nanocomposite has the highest activity against E. coli. Further, the antibacterial assay was carried out by using the micro broth dilution method to corroborate the results found in the AWD method. Table 1 illustrates the effective percentage (\%) inhibition and the respective MIC of each strain. It could be noticed from AWD method that $E$. coli among all the selected bacterial strains exhibited an augmented bactericidal inhibition \%. In contrast, all three strains exhibited a more than $90 \%$ inhibition rate. Among the three MIC studies as shown in Table $1, \mathrm{IC}_{50}$ calculations show a pronounced antibacterial activity of $B$. subtilis $(90.67 \pm 0.32 \mu \mathrm{g} / \mathrm{ml})$, P. aeruginosa $(114.95 \pm 0.79 \mu \mathrm{g} / \mathrm{ml})$, and against $E$. coli $(72.98 \pm 0.27 \mu \mathrm{g} / \mathrm{ml})$, which has been supported and corroborated with several previous publications in the similar lines.

It could be understood from the observations of antibacterial assays that $\mathrm{CuO}$ nanoparticles exhibited a broad spectrum antibacterial potentiality against Gram-positive and Gram-negative strains [11].

The exact mechanism of nanomaterials-mediated potential antibacterial activity is not appropriately established. However, various possible mechanisms were put forwarded in the research reports regarding the antibacterial effect of
Fig. 6 FE-SEM micrographs of untreated E. coli cells (A) showing intact and high electron density morphology (green arrow). (B) The considerable size of adhered nanocomposites was observed (brick red arrow) attached to the surface of the cells of the bacteria, and disrupted cell wall and membrane leakage was observed. The scale bar is $5 \mu \mathrm{m}$
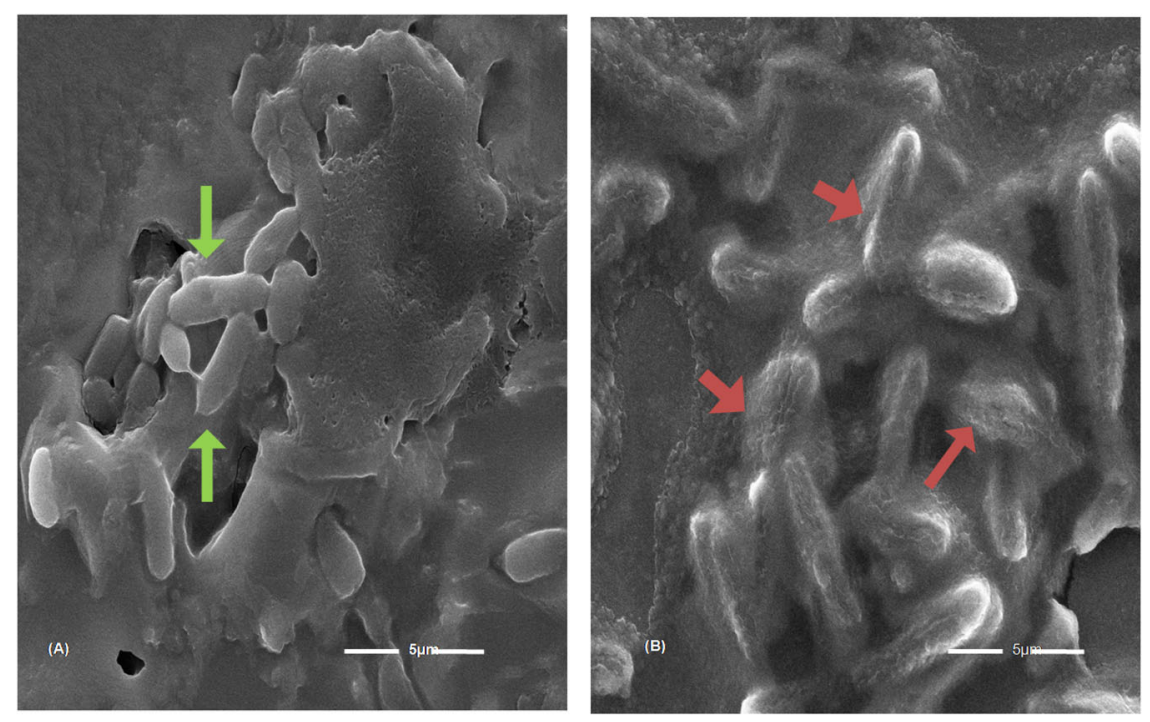

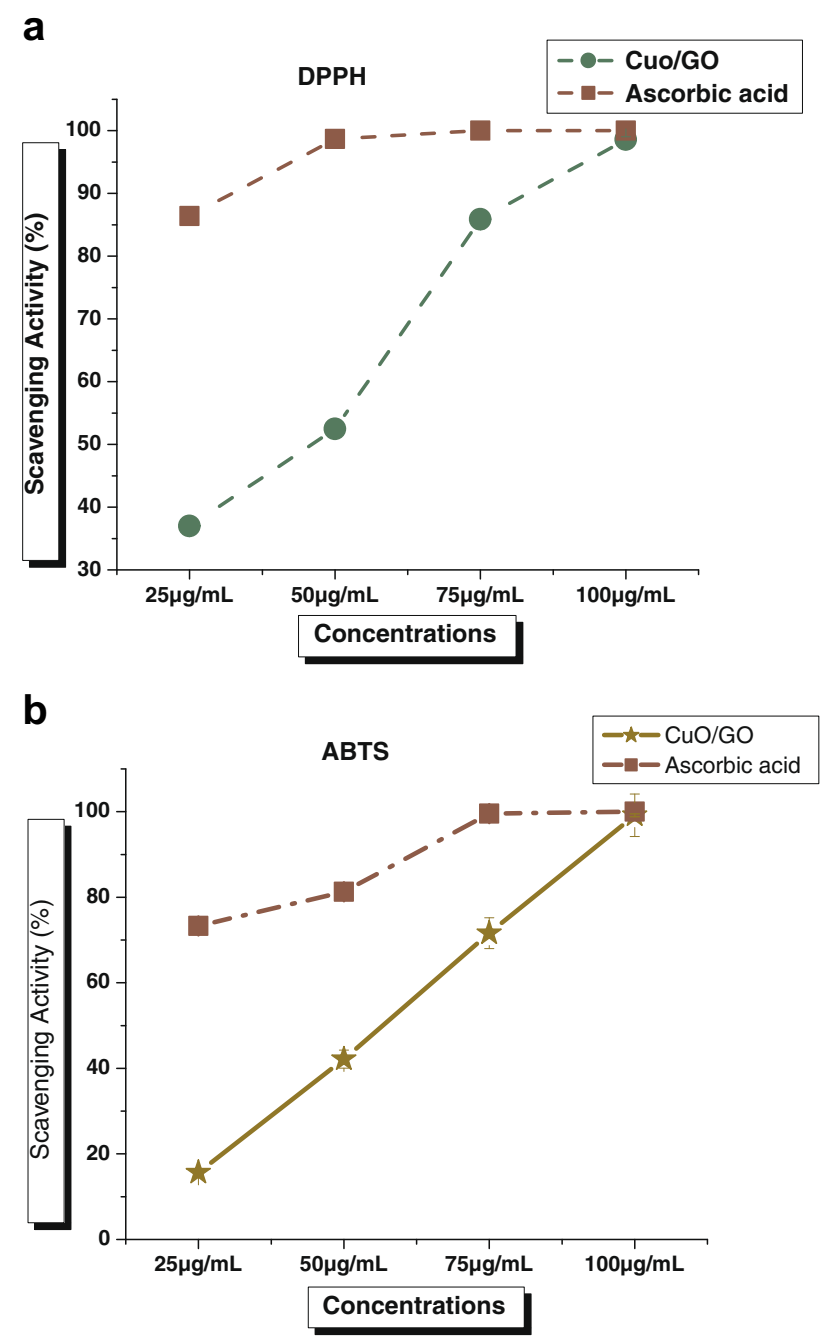

Fig. 7 Antioxidant activity of $\mathrm{CuO} / \mathrm{GO}$ nanocomposite in terms of radical scavenging activity (A) DPPH and (B) ABTS. Error bar represents the standard deviation of the mean. ${ }^{*} p \leq 0.05$

nanomaterials. It was proposed that nanomaterial permeate the cell wall of the bacteria because of their adhering ability, eventually altering the bacterial membranes' structural integrity and resulting in penetration inside the bacterial cells leading to cidal activity of the bacterial cells [23].On the other hand, it has also been speculated by several studies that the permeated nanomaterials inside the bacterial cells cause the net interactions with the vital macromolecules like DNA, proteins of the bacterial cells resulting in the production of Reactive Oxygen Species radicals causing degradation of the cellular integrity leading to death of the [24]. Several cysteine bonds and other enzymatic importance bonds are vulnerable to attack by several nanomaterials, leading to the deformations in the bacterial cells' intrinsic bonding patterns, resulting in breakage and denaturation causing a death response the bacterial cells against the nanomaterials [25]. It has also been reported that several

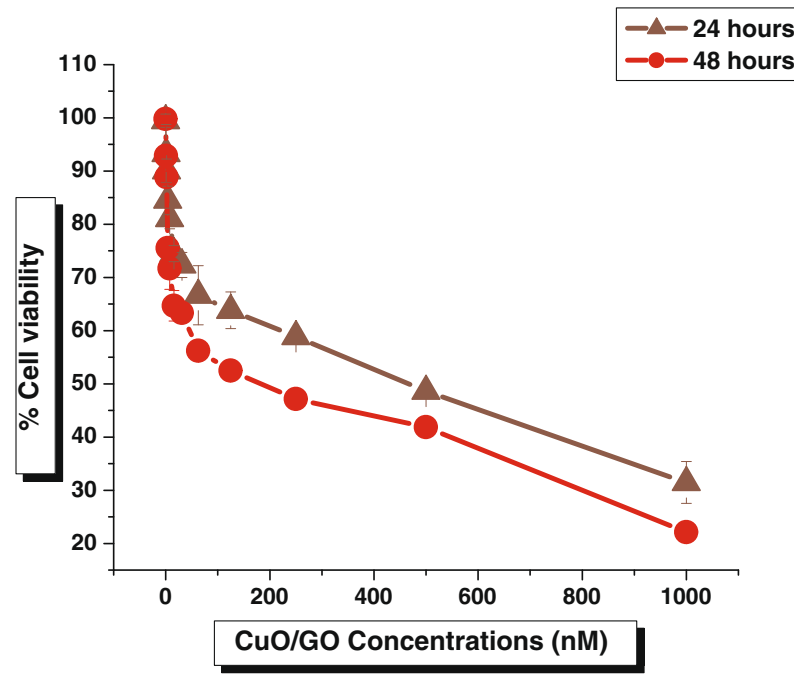

Fig. 8 Cell viability of A-431 after treatment with different $\mathrm{CuO} / \mathrm{GO}$ nanocomposites concentrations after 24 and $48 \mathrm{~h}$. Error bar represents the standard deviation of the mean $* p \leq 0.05$

nanomaterials of importance attach the intermittent sulphur and phosphorous groups in the DNA molecules of the bacterial cells, resulting in deformations in the basic architecture of the bacterial cells leading to death [26]. Such augmented antibacterial activities achieved for the $\mathrm{CuO} / \mathrm{GO}$ nanocomposites could be harnessed for designing an effective therapeutic and harbouring diagnostic attributes device, which can aid in the fight against drug-resistant medically important microbes [27].

\subsection{Underlying mechanism of antibacterial activity and FESEM analyses}

In order to understand the nature of the interaction between the bacterial cells and the as-prepared nanocomposites, the ultrastructural aspects of the treated bacterial cultures and the respective control cultures were determined using FE-SEM analyses as seen in Fig. 6. It could be clearly understood from Fig. 6 that upon getting into contact with the nanocomposites, the uniform nature of the surface of $E$. coli has been seemed to be corrugated as when compared to the untreated cultures of the E. coli culture. Such induction in the unevenness in the bacterial outer surface architecture is mainly because of the fact that upon $\mathrm{CuO} / \mathrm{GO}$ nanocomposite interactions at the outer membrane of the bacterial surface, there is an interplay of redox reaction between the composite and the bacterial cellular outer membranes. The resulting oxidation/ reduction process causes a net rupturing in the uniform cellular architecture of the outer bacterial membrane, causing a state of vulnerability in the bacterial membranes for permeating the nanocomposites inside the bacterial interior, resulting in destabilizing the inner chemistry of the cells causing some augmented bactericidal responses. 


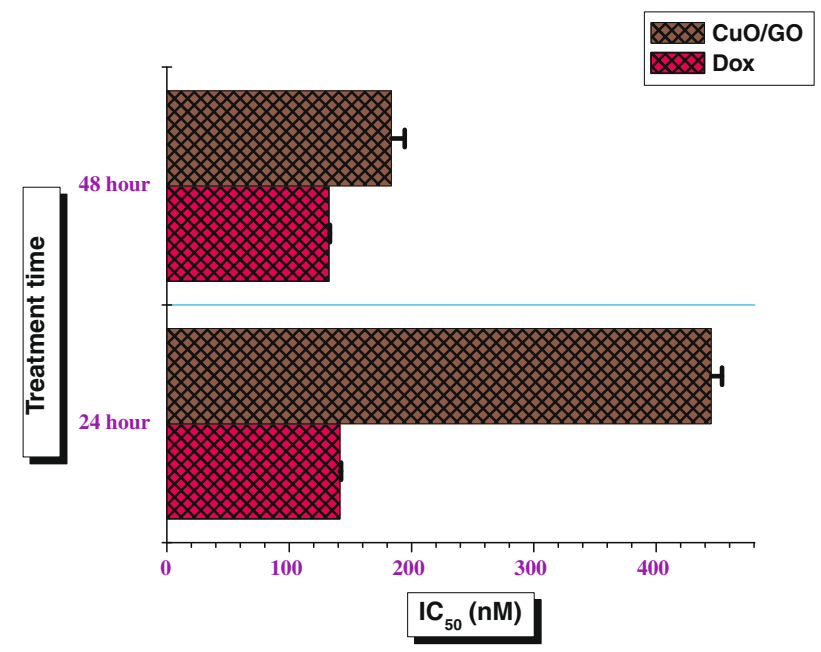

Fig. 9 Cell viability assay of A-431 after treatment with $\mathrm{CuO} / \mathrm{GO}$ nanocomposite and doxorubicin (control) in $\mathrm{IC}_{50}$ calculations. Error bar represents the standard deviation of the mean $* p \leq 0.05$. Significant difference $(p \leq 0.05)$ within a parameter between two lines is denoted by an asterisk

\subsection{Antioxidant activity}

The antioxidant activity assessment of nanomaterials or nanocomposites is one of the most crucial studies prior to use in any biomedical application system [28]. Antioxidants have a significant impact on the performance of all biosystems [29]. The generation of free radicals is very frequent in biological systems due to the interaction of biomolecules present in the system with molecular oxygen [30]. The antioxidant activity of synthetic nanomaterials has been evaluated before its real-time application concerning any living system (Brand-Williams et al., 1995). The DPPH scavenging assay is prevalent in evaluating the antioxidant property of newly formed materials utilizing tests that employ DPPH radicals. In the DPPH assay, the antioxidant entities present in the test sample reduce the stable nitrogen radical DPPH and produce the reduced form of DPPH by donating oxygen atoms. In the current work, the DPPH scavenging of $\mathrm{CuO} / \mathrm{GO}$ nanocomposite was determined by estimatingIC $\mathrm{I}_{50}$ parameter, which illustrates the capability to scavenge free radicals.

For $\mathrm{CuO} / \mathrm{GO}$ nanocomposite, the $\mathrm{IC}_{50}$ value was $44.86 \pm 1.74 \mu \mathrm{g} / \mathrm{ml}$ (Fig. 7), indicating significant antioxidant potential in DPPH scavenging. Additionally, the ABTS radical scavenging activity was also studied to prove more safe and potential use of $\mathrm{CuO} / \mathrm{GO}$ nanocomposite in biomedical devices for efficient applications in different bio applications. The $\mathrm{IC}_{50}$ value was calculated as $55.70 \pm 0.19 \mu \mathrm{g} / \mathrm{ml}$ (Fig. 7) for $\mathrm{CuO} / \mathrm{GO}$ nanocomposite in ABTS radical scavenging activity. Previously, there were many reports have been published regarding the potential antioxidant activities by using individual $\mathrm{CuO}$ nanoparticles and $\mathrm{GO}$ nanosheets, and the current antioxidant results were highly supported by the previous studies $[18,31]$.

\subsection{Cytotoxic activity against A-431 cell lines}

The A-431cancer cells were treated with $\mathrm{CuO} / \mathrm{GO}$ nanocomposites in the culture at varying concentrations $(0.97 \mathrm{nM}$ to $1000 \mathrm{nM}$ ) for $24 \mathrm{~h}$ at $37^{\circ} \mathrm{C}$. The methylthiazolyldiphenyltetrazolium bromide [MTT] assay was used to evaluate epidermoid carcinoma (A-431) cell viability upon treatment with $\mathrm{CuO} / \mathrm{GO}$ nanocomposites (Fig. 8). The concentrationdependent effect of $\mathrm{CuO} / \mathrm{GO}$ nanocomposites on A-431 cell viability was observed from assay results. The percentage of cell viability, however, slowly reduced as the $\mathrm{CuO} / \mathrm{GO}$ concentration increased. The treatment of the cancer cells with a $\sim 1000 \mathrm{nM} \mathrm{CuO} / \mathrm{GO}$ for $24 \mathrm{~h}$ decreased cell viability to $\sim 31.46 \%$.

It could be observed that upon an increase in the concentration of the $\mathrm{CuO} / \mathrm{GO}$ nanocomposites, the percentage of the viable cancer cells seems to be concomitantly reduced. It is observed that the percentage of viable cells of $\sim 48.63 \%$ and $81.06 \%$, respectively were detected when the cells were treated with $500 \mathrm{nM}$ and $7.8 \mathrm{nM}$ concentrations of $\mathrm{CuO} / \mathrm{GO}$ nanocomposites after $24 \mathrm{~h}$ incubation. On the other hand, as shown in Fig. 9, upon treatment of the test solution cells with the nanocomposites of same concentration $\sim 500 \mathrm{nM}$ and $7.8 \mathrm{nM}$, the viability seems to be reduced slightly of $\sim 41.86$ and $71.67 \%$ with the incubation timings after $48 \mathrm{~h}$. Such differential cytotoxic responses indicate that a dose-dependent response of A-431 cancer cells exhibits a negligible influence of time-dependent cytotoxicity responses when tested in similar cell lines at the same concentration dosages in-vitro.

Many previous research reports have supported timedependent and dose-dependent cytotoxicity against A-431cells [31, 32]. It has been investigated that ROS formation during the cellular metabolism takes place after expose to test sample, plays a vital role in the mechanism of cytotoxicity of $\mathrm{CuO} / \mathrm{GO}$ nanocomposites in epidermoid carcinoma [A-431] [33]. It has been further speculated that upon introduction of the $\mathrm{CuO} / \mathrm{GO}$ nanocomposites into the cells, the intrinsic vital organelle of the cells, also known as the 'power house' of the cell 'mitochondrion' is also gets targeted severely because of the formation of free radicals of $\mathrm{O}^{-}, \mathrm{O}^{2-}$ etc. causing a disability in the essential metabolism in the cells, leading to the death of the cells [34].

The $\mathrm{IC}_{50}$ value of $\mathrm{CuO} / \mathrm{GO}$ was found to be $444.96 \pm$ $8.87 \mathrm{nM}$ in $24 \mathrm{~h}$ and $183.51 \pm 10.99 \mathrm{nMin} 48 \mathrm{~h}$ of treatment in A-431 cells. However, the $\mathrm{IC}_{50}$ of doxorubicin [control] was found $141.33 \pm 1.00 \mathrm{nM}$ in $24 \mathrm{~h}$ and $132.46 \pm$ $0.94 \mathrm{nMin} 48 \mathrm{~h}$ of exposure to the cancer cells. It was 
observed that the $\mathrm{IC}_{50}$ value of $\mathrm{CuO} / \mathrm{GO}$ is almost very similar to doxorubicin in $48 \mathrm{~h}$ of exposure (Fig. 9). Hence, $\mathrm{CuO} / \mathrm{GO}$ nanocomposites can be considered potential candidates for the oncology treatments application [31].

\section{Conclusion}

The as-prepared nanocomposites exhibited tremendous antimicrobial and antioxidant implications when tested in-vitro, forming a part of the therapeutic activity of the nanocomposites. The average particle size of the formed nanocomposites came about $\sim 20 \mathrm{~nm}$, which is significant enough to elicit biological activities when tested. The possible diagnostic and drug-target interaction for designing a possible theranostic agent has been tried to be explained using mathematical modelling of drug-target interactions and its underlying pharmacodynamics phenomenon. The pristine electrochemical, Physico-chemical properties of $\mathrm{CuO}$ nanoparticles, along with the water-soluble GO, makes the composite a robust platform for designing futuristic nano-electromechanical devices which can be used for sensing the slightest analytes by tuning the pristine direct band gap features and p-type nature of the $\mathrm{CuO}$ nanoparticle entity in the biomedical domain.

Acknowledgements We are thankful to the respective universities for providing necessary research facilities. The authors would also like to extend their sincere thanks to the Deanship of Scientific Research at King Khalid University, Saudi Arabia for supporting this work through grant number R.G.P-2/22/42.

Author contributions K.B., Y.K.M., A.K.M. conceptualized, designed the experiments and wrote the whole manuscript. A.S., A.G.A, M.P. partially helped in enriched the manuscript and perform some biophysical analysis. A.B., D.D., S.K.A, B.P.P. vigorously edited the manuscript. T.K.M. and A.A.H. also revised the manuscript minutely and finally all authors approved for the communication the manuscript.

\section{Compliance with ethical standards}

Conflict of interest The authors declare no competing interests.

Publisher's note Springer Nature remains neutral with regard to jurisdictional claims in published maps and institutional affiliations.

Open Access This article is licensed under a Creative Commons Attribution 4.0 International License, which permits use, sharing, adaptation, distribution and reproduction in any medium or format, as long as you give appropriate credit to the original author(s) and the source, provide a link to the Creative Commons license, and indicate if changes were made. The images or other third party material in this article are included in the article's Creative Commons license, unless indicated otherwise in a credit line to the material. If material is not included in the article's Creative Commons license and your intended use is not permitted by statutory regulation or exceeds the permitted use, you will need to obtain permission directly from the copyright holder. To view a copy of this license, visit http://creativecommons. org/licenses/by/4.0/.

\section{References}

1. Huang Y, Xie X, Li M, Xu M, Long J. Copper circuits fabricated on flexible polymer substrates by a high repetition rate femtosecond laser-induced selective local reduction of copper oxide nanoparticles. Opt Expr. 2021;29:4453-63.

2. Song J, Xu L, Zhou C, Xing R, Dai Q, Liu D, et al. Synthesis of graphene oxide based $\mathrm{CuO}$ nanoparticles composite electrode for highly enhanced nonenzymatic glucose detection. ACS Appl Mater Interfaces. 2013;5:12928-34. https://doi.org/10.1021/am403508f.

3. Singh P, Singh KR, Singh J, Das SN, Singh RP. Tunable electrochemistry and efficient antibacterial activity of plant-mediated copper oxide nanoparticles synthesized by Annona squamosa seed extract for agricultural utility. RSC Adv. 2021;11: 18050-60.

4. El-Shafai NM, Abdelfatah M, El-Mehasseb IM, Ramadan MS, Ibrahim MM, El-Shaer A, et al. Enhancement of electrochemical properties and photocurrent of copper oxide by heterojunction process as a novel hybrid nanocomposite for photocatalytic antifouling and solar cell applications. Sep Purif Technol. 2021;267:118631.

5. Khan S, Shah SS, Anjum MAR, Khan MR, Janjua NK. Electrooxidation of ammonia over copper oxide impregnated $\gamma$-Al2O3 nanocatalysts. Coatings. 2021;11:313.

6. Noreen M, Khan MNM, Ahmed A, Hussain G. A perspective study on copper oxide nanoparticles and their role in different fields of biomedical sciences. Int J Sci Res Eng Dev. 2020;3: 1246-56.

7. Maor I, Asadi S, Korganbayev S, Dahis D, Shamay Y, Schena E, et al. Laser-induced thermal response and controlled release of copper oxide nanoparticles from multifunctional polymeric nanocarriers. Sci Technol Adv Mater. 2021;22:218-33.

8. Jana ID, Kumbhakar P, Banerjee S, Gowda CC, Kedia N, Kuila $\mathrm{SK}$, et al. Copper nanoparticles-graphene composite-based transparent surface coating with antiviral activity against Influenza virus. ACS Appl Nano Mater. 2021;4:352-62.

9. Rabiee N, Bagherzadeh M, Kiani M, Ghadiri AM, Etessamifar F, Jaberizadeh AH, et al. Biosynthesis of copper oxide nanoparticles with potential biomedical applications. Int J Nanomed. 2020;15: 3983.

10. Siddiqi KS, Husen A. Current status of plant metabolite-based fabrication of copper/copper oxide nanoparticles and their applications: a review. Biomater Res. 2020;24:1-15.

11. Bezza FA, Tichapondwa SM, Chirwa EM. Fabrication of monodispersed copper oxide nanoparticles with potential application as antimicrobial agents. Sci Rep. 2020;10:1-18.

12. Sackey J, Nwanya A, Bashir AKH, Matinise N, Ngilirabanga JB, Ameh AE, et al. Electrochemical properties of Euphorbia pulcherrima mediated copper oxide nanoparticles. Mater Chem Phys. 2020;244:122714.

13. Mohanta YK, Biswas K, Rauta PR, De D, Hashem A, Alqarawi AA, et al. Development of graphene oxide nanosheets as potential biomaterials in cancer therapeutics: an in-vitro study against breast cancer cell line. J Inorg Organomet Mater Polym. 2021;31:4236-49.

14. Lu BY, Zhu GY, Yu CH, Chen GY, Zhang CL, Zeng X, et al. Functionalized graphene oxide nanosheets with unique three-inone properties for efficient and tunable antibacterial applications. Nano Res. 2021;14:185-90.

15. Thangamani JG, Pasha SK. Hydrothermal synthesis of copper (II) oxide-nanoparticles with highly enhanced BTEX gas sensing performance using chemiresistive sensor. Chemosphere. 2021;277:130237.

16. Das NS, Gogoi KK, Das S, Chowdhury A. Spectroscopic and structural investigation of graphene oxide synthesized via 
Hummers' method. In: Recent advances in sustainable technologies. Singapore: Springer; 2021. p. 207-13.

17. Alayande AB, Obaid M, Kim IS. Antimicrobial mechanism of reduced graphene oxide-copper oxide $(\mathrm{rGO}-\mathrm{CuO})$ nanocomposite films: the case of Pseudomonas aeruginosa PAO1. Mater Sci Eng C. 2020;109:110596 https://doi.org/10.1016/j.msec.2019.110596.

18. Dobrucka R. Antioxidant and catalytic activity of biosynthesized $\mathrm{CuO}$ nanoparticles using extract of galeopsidis herba. J Inorg Organomet Polym Mater. 2018;28:812-9. https://doi.org/10.1007/ s10904-017-0750-2.

19. Arulkumar A, Rosemary T, Paramasivam S, Rajendran R. Phytochemical composition, in vitro antioxidant, antibacterial potential and GC-MS analysis of red seaweeds (Gracilaria corticata and Gracilaria edulis) from Palk Bay, India. Biocatal Agric Biotechnol. 2018;15:63-71.

20. Vijayabaskar P, Shiyamala V. Antioxidant properties of seaweed polyphenol from Turbinaria ornate (Turner) J.Agardh, 1848. Asian Pac J Trop Biomed. 2012;2:S90-8.

21. Nayak D, Ashe S, Rauta PR, Kumari M, Nayak B. Bark extract mediated green synthesis of silver nanoparticles: Evaluation of antimicrobial activity and antiproliferative response against osteosarcoma. Mater Sci Eng C. 2016;58:44-52.

22. Ganesan K, Jothi VK, Natarajan A, Rajaram A, Ravichandran S, Ramalingam S. Green synthesis of Copper oxide nanoparticles decorated with graphene oxide for anticancer activity and catalytic applications. Arab J Chem. 2020;13:6802-14. https://doi.org/10. 1016/j.arabjc.2020.06.033.

23. Mohanta YK, Panda SK, Bastia AK, Mohanta TK. Biosynthesis of silver nanoparticles from Protium serratum and investigation of their potential impacts on food safety and control. Front Microbiol. 2017;8:626.

24. Patra JK, Baek K-H Antibacterial activity and synergistic antibacterial potential of biosynthesized silver nanoparticles against foodborne pathogenic bacteria along with its anticandidal and antioxidant effects. Front Microbiol. 2017;08 February:1-14. https://doi.org/10.3389/fmicb.2017.00167.

25. Swamy M, Mohanty S, Jayanta K, Subbanarasiman B. The green synthesis, characterization, and evaluation of the biological activities of silver nanoparticles synthesized from Leptadenia reticulata leaf extract. Appl Nanosci. 2015;5:73-81.

26. Ramesh P, Kokila T, Geetha D. Plant mediated green synthesis and antibacterial activity of silver nanoparticles using Emblica officinalis fruit extract. Spectrochim Acta A Mol Biomol Spectrosc. 2015;142:339-43.

27. Bhavyasree PG, Xavier TS. Green synthesis of Copper Oxide/ Carbon nanocomposites using the leaf extract of Adhatoda vasica Nees, their characterization and antimicrobial activity. Heliyon. 2020;6:e03323 https://doi.org/10.1016/j.heliyon.2020.e03323.

28. Frankel EN, Meyers AS. In search of better methods to evaluate natural antioxidants and oxidative stability in food lipids. J Sci Food Agric. 2000;80:1925-41.

29. Gupta A, Jamatia R, Patil RA, Ma YR, Pal AK. Copper oxide/ reduced graphene oxide nanocomposite-catalyzed synthesis of flavanones and flavanones with triazole hybrid molecules in one pot: a green and sustainable approach. ACS Omega. 2018;3:7288-99.

30. Davies KJ. Protein damage and degradation by oxygen radicals. I. general aspects. J Biol Chem. 1987;262:9895-901. https://doi.org/ 10.1016/s0021-9258(18)48018-0.

31. Subashini K, Prakash S, Sujatha V. Polymer nanocomposite prepared using copper oxide nanoparticles derived from Sterculia foetida leaf extract with biological applications. Mater Res Expr. 2020;7:115308.

32. Nayak D, Minz AP, Ashe S, Rauta PR, Kumari M, Chopra P, et al. Synergistic combination of antioxidants, silver nanoparticles and chitosan in a nanoparticle based formulation: Characterization and cytotoxic effect on MCF-7 breast cancer cell lines. J Colloid Interface Sci. 2016;470:142-52. https://doi. org/10.1016/j.jcis.2016.02.043.

33. Elias L, Taengua R, Frígols B, Salesa B, Serrano-Aroca Á. Carbon nanomaterials and LED irradiation as antibacterial strategies against gram-positive multidrug-resistant pathogens. Int J Mol Sci. 2019;20:3603.

34. Bulcke F, Dringen R. Copper oxide nanoparticles stimulate glycolytic flux and increase the cellular contents of glutathione and metallothioneins in cultured astrocytes. Neurochem Res. 2015;40:15-26. 